\title{
Anterior Cerebral Artery
}

National Cancer Institute

\section{Source}

National Cancer Institute. Anterior Cerebral Artery. NCI Thesaurus. Code C12829.

One of the two arteries arising from the internal carotid artery and being part of the Circle of Willis. Both left and right anterior cerebral arteries are connected by the anterior communicating artery. 